\title{
Blended learning e as mudanças no ensino superior: a proposta da sala de aula invertida
}

\section{Blended Learning and Changes in Higher Education: the inverted classroom proposal}

\author{
José Armando Valente ${ }^{1}$
}

\begin{abstract}
RESUMO
As tecnologias digitais de informação e comunicação (TDIC) proporcionaram importantes mudanças na educação a distância, que até o início dos anos 1980 era baseada no material impresso produzido e enviado aos alunos. Com as tecnologias foram criadas diversas modalidades de ensino a distância, inclusive o blended learning, que combina atividades presenciais e atividades educacionais a distância, realizadas por meio das TDIC. Há diferentes maneiras de combinar as atividades presenciais e a distância, sendo a sala de aula invertida ou flipped classroom uma delas. Segundo essa abordagem, o conteúdo e as instruções sobre um determinado assunto curricular não são transmitidos pelo professor em sala de aula. $\mathrm{O}$ aluno estuda o material antes de ele frequentar a sala de aula, que passa a ser o lugar de aprender ativamente, realizando atividades de resolução de problemas ou projetos, discussões, laboratórios etc., com o apoio do professor e colaborativamente dos colegas. O objetivo do artigo é discutir as diferentes modalidades do blended learning e da sala de aula invertida, como as TDIC são usadas em diferentes modelos de implantação dessa abordagem pedagógica, como a sala de aula invertida pode ser implantada e os pontos positivos e negativos sobre a sala de aula invertida apresentados por diferentes autores.

Palavras-chave: sala de aula invertida; aprendizagem ativa; aprendizagem híbrida; tecnologias educacionais; inovação pedagógica.
\end{abstract}

DOI: $10.1590 / 0104-4060.38645$

1 Universidade Estadual de Campinas (UNICAMP), Departamento de Multimeios, Mídia e Comunicação do Instituto de Artes. Campinas, São Paulo, Brasil. Rua Elis Regina, 50. CEP: $13083-854$. 


\begin{abstract}
Digital information and communication technologies (DICT) provided important changes in distance education which, until the beginning of the 1980 s, was based on printed material produced and sent to students. With the use of technologies, different types of distance education were created, including blended learning that combines face-to-face classroom activities and educational activities developed online through DICT. There are various ways to combine online and classroom activities, and one of them is the flipped classroom. According to this approach the content and instructions on a particular curriculum subject are not transmitted by the teacher in the classroom. The student studies the material before attending the classroom. The flipped classroom is used for active learning, for solving problems or projects, discussions, practical activities in laboratories, etc., with support from the teacher and from peers collaboratively. The objective of this article is to discuss the different types of blended learning and the flipped classroom, how DICT are used in different models of this pedagogical approach, how the flipped classroom can be implemented, and the positive and negative aspects that have been presented by various authors.
\end{abstract}

Keywords: inverted classroom; active learning; blended learning; educational technology; educational innovation.

\title{
Introdução
}

O ensino superior enfrenta atualmente dois grandes desafios. Um é sobre as salas de aula cada vez mais vazias, ou quando o aluno está presente, ele está fazendo outra coisa diferente do que acompanhar a aula. Outro desafio é a incapacidade de atender a grande demanda do número de alunos que querem ingressar no ensino superior. Assim, o modelo de universidade que faz pesquisa, gera conhecimento e distribui este conhecimento para poucos já não se sustenta mais. Como afirmam Tapscott e Williams:

O atual modelo pedagógico, que constitui o coração da universidade moderna, está se tornando obsoleto. No modelo industrial de produção em massa de estudantes, o professor é o transmissor. [...]. A aprendizagem baseada na transmissão pode ter sido apropriada para uma economia e uma geração anterior, mas cada vez mais ela está deixando de atender às necessidades de uma nova geração de estudantes que estão prestes a 
entrar na economia global do conhecimento (TAPSCOTT; WILLIAMS, 2010, p. 18-19).

O processo de ensino e aprendizagem baseado na transmissão de informação foi criticado por John Dewey há mais de um século como sendo antiquado e ineficaz (DEWEY, 1916). Sua proposta era a aprendizagem baseada no fazer, "hands-on". O argumento utilizado é que as aulas expositivas partem do pressuposto de que todos os estudantes aprendem no mesmo ritmo e absorvendo informação ouvindo o professor. Na verdade a sala de aula tradicional é um subproduto do industrialismo, idealizada na concepção da linha de montagem (VALENTE, 2007) e com propósito de treinar os alunos segundo as conformidades do modelo industrial. Como observado por Davidson (2011), independente do conteúdo a ser trabalhado na sala de aula, a maneira como isso acontece tem como objetivo construir uma prática disciplinar voltada para a fábrica ou empresa, que mais tarde poderá contratar seus graduados.

Considerando que o modelo industrial está sendo gradativamente substituído pelo modelo de produção e de serviço baseado na economia do conhecimento, diversos órgãos como Unesco (2009) e mesmo os PCNs (BRASIL, 1998) têm proposto métodos de ensino alternativos, explorando a colaboração, a exploração, a investigação, o fazer, mais adequados para a idade pós-industrial.

De fato, as teorias sobre como as pessoas aprendem, como relatadas no trabalho de Bransford, Brown e Cocking (2000), corroboram com essa nova visão de ensino. Dentre as três principais conclusões sobre a ciência da aprendizagem identificadas por esses autores, uma delas é extremamente importante para entender o novo papel do processo de ensino e de aprendizagem. Eles afirmam que "para desenvolver a competência em uma área de investigação, os alunos devem: a) ter uma profunda base de conhecimento factual, b) compreender fatos e ideias no contexto de um quadro conceitual e c) organizar o conhecimento de modo a facilitar sua recuperação e aplicação" (tradução livre, p. 16). Isso significa que além de reter a informação, o aprendiz necessita ter um papel ativo para significar e compreender essa informação segundo conhecimentos prévios, construir novos conhecimentos, e saber aplicá-los em situações concretas.

As implicações educacionais dessa afirmação são claras. Especificamente com relação à sala de aula, ela terá de ser repensada na sua estrutura, bem como na abordagem pedagógica que tem sido utilizada.

Nesse sentido, têm surgido diversas propostas de práticas pedagógicas alternativas, como a aprendizagem ativa, na qual, em oposição à aprendizagem passiva, bancária (FREIRE, 1987), baseada na transmissão de informação, o aluno assume uma postura mais participativa, na qual ele resolve problemas, 
desenvolve projetos e, com isto, cria oportunidades para a construção de conhecimento. Diversas estratégias têm sido utilizadas para promover a aprendizagem ativa, como a aprendizagem baseada na pesquisa, o uso de jogos, a Aprendizagem Baseada em Problemas (ABP), ou a Aprendizagem Baseada em Problemas e por Projetos (ABPP). No caso da ABP, a ênfase é a resolução de problemas ou as situações significativas, contextualizadas no mundo real. $\mathrm{Na}$ ABPP os problemas ou projetos são enfrentados e estudados de forma coletiva e colaborativa por um grupo de aprendizes e não individualmente.

A dificuldade com essas abordagens é a adequação do problema de acordo com o currículo que está sendo trabalhado e com o nível de conhecimento dos alunos. No caso dos projetos, em geral escolhidos de acordo com o interesse de cada aluno ou grupo de alunos, é possível encontrar uma diversidade de temas, tornando bastante difícil para o professor mediar o processo de aprendizagem. Além disso, essas abordagens são difíceis de serem implantadas em salas com um grande número de alunos.

No entanto, essas dificuldades têm sido superadas à medida que as tecnologias digitais de informação e comunicação (TDIC) estão sendo utilizadas na educação e passam a fazer parte das atividades de sala de aula. Essas tecnologias têm alterado a dinâmica da escola e da sala de aula como, por exemplo, a organização dos tempos e espaços da escola, as relações entre o aprendiz e a informação, as interações entre alunos, e entre alunos e professor. A integração das TDIC nas atividades da sala de aula tem proporcionado o que é conhecido como blended learning ou ensino híbrido, sendo que a "sala de aula invertida" (flipped classroom) é uma das modalidades que têm sido implantadas tanto no Ensino Básico quanto no Ensino Superior.

O objetivo deste artigo é discutir as diferentes modalidades do blended learning e, em especial a sala de aula invertida, explorando como as TDIC têm sido utilizadas na implantação dessa abordagem pedagógica, as razões para a sua implantação, e os aspectos positivos e negativos que têm sido apresentados sobre as experiências usando a abordagem da sala de aula invertida no Ensino Superior.

\section{O blended learning ou ensino híbrido}

A presença das TDIC na educação não promoveu mudanças substanciais na sala de aula, porém elas provocaram profundas transformações na Educação a Distância (EaD). Até o final dos anos 80 (século passado), a EaD estava fun- 
damentalmente baseada no material impresso, que era devidamente preparado, enviado ao aprendiz e utilizado de acordo com a sua disponibilidade de tempo e local de estudo. Estas condições caracterizavam o ensino feito a distância, demarcando claramente uma separação espacial e temporal entre o professor e os aprendizes.

As TDIC criaram meios e condições para alterar diversos aspectos da $\mathrm{EaD}$, como as concepções teóricas, as abordagens pedagógicas, as finalidades da $\mathrm{EaD}$ e os processos de avaliação da aprendizagem dos alunos. Diversos termos são utilizados para identificar o tipo de separação geográfica e temporal que caracteriza as atividades de EaD, como observado por Guri-Rosenblit (2009). Os termos "educação a distância" e "e-learning", em geral, são usados com o mesmo significado, sendo o e-learning visto como uma nova versão da $\mathrm{EaD}$ na qual as atividades são mediadas pelas TDIC. Além disso, para diferenciar as diversas formas dessa nova $\mathrm{EaD}$, a literatura internacional tem usado uma série de outros termos como, por exemplo, web-based education, on-line education, virtual classroom, distributed learning, etc. Nos Estados Unidos, "distance education" é definida como sendo mediada pelas TDIC (GURI-ROSENBLIT, 2009). No Brasil ocorre o mesmo. Pela falta de um termo que defina explicitamente o e-learning, "educação a distância" tem sido usado para designar o ensino a distância mediado pelas TDIC. O termo online é utilizado para os cursos realizados totalmente a distância, como os Cursos Online Abertos e Massivos (Massive Open Online Courses - MOOCs), desenvolvidos por consórcios de universidades americanas, como o edX - iniciativa do Massachusetts Institute of Technology (MIT) e da Harvard University (EDX, 2014) - ou o CourseWare, proposto pela Stanford University (COURSEWARE, 2014); ou mesmo em alguns cursos desenvolvidos por universidades brasileiras por intermédio da Universidade Aberta do Brasil (UAB), principalmente naqueles em que somente as avaliações são realizadas presencialmente.

Esta pluralidade de termos existe pelo fato de estarmos em uma fase de transição, na qual ainda coexistem atividades de $\mathrm{EaD}$ tradicionais, baseadas em material impresso ou mesmo em suportes tecnológicos como $\mathrm{CD}$, rádio e TV; atividades de EaD efetuadas por intermédio das TDIC, principalmente por meio dos ambientes virtuais de aprendizagem; e atividades de e-learning. Assim, a $\mathrm{EaD}$ via TDIC e o e-learning se sobrepõem em algumas situações.

Porém, nem todas as atividades de e-learning são realizadas a distância. Muito pelo contrário, a separação geográfica e temporal não são características fundamentais do e-learning. Essa abordagem educacional tem sido usada como complemento de atividades educacionais presenciais, para incrementar atividades de pesquisa, auxiliar a mobilidade e colaboração entre professores e alunos, 
e para facilitar o acesso à informação ou até mesmo o uso das TDIC no desenvolvimento de projetos ou atividades curriculares cumpridas presencialmente.

Outra modalidade de e-learning é quando parte das atividades são realizadas totalmente a distância e parte é realizada em sala de aula, caracterizando o que tem sido denominado de ensino híbrido, misturado ou blended learning.

O blended learning tem sido utilizado tanto no Ensino Básico quanto no Ensino Superior, principalmente nos Estados Unidos e Canadá. A literatura sobre essa modalidade de EaD é bastante vasta, como indica o relatório "Definindo Blended Learning" (FRIESEN, 2012, tradução nossa).

Embora baseado em experiências de uso do blended learning no Ensino Básico americano (K-12), Staker e Horn (2012) apresentam uma definição bastante completa para essa modalidade de ensino e uma taxonomia de formas de uso que é bastante ampla. Eles definem blended learning como um programa de educação formal que mescla momentos em que o aluno estuda os conteúdos e instruções usando recursos on-line, e outros em que o ensino ocorre em uma sala de aula, podendo interagir com outros alunos e com o professor. Na parte realizada on-line o aluno dispõe de meios para controlar quando, onde, como e com quem vai estudar. Esses autores enfatizam o aspecto formal para diferenciar as situações de aprendizagem que acontecem informalmente. No caso do blended learning o conteúdo e as instruções devem ser elaborados especificamente para a disciplina ao invés de usar qualquer material que o aluno acessa na internet. Além disso, a parte presencial deve necessariamente contar com a supervisão do professor, valorizar as interações interpessoais e ser complementar às atividades on-line, proporcionado um processo de ensino e de aprendizagem mais eficiente, interessante e personalizado.

Esses autores definem quadro modelos que categorizam a maioria dos programas de ensino híbrido ou blended: flex, blended misturado, virtual enriquecido e rodízio. No modelo flex, a âncora do processo de ensino e de aprendizagem é o conteúdo e as instruções que o aluno trabalha via plataforma on-line. A parte flexível e adaptável corresponde ao tipo de suporte que ele recebe na situação presencial, podendo ser um apoio substancial de um professor certificado, ou uma pequena ajuda de um adulto que auxilia o aluno de acordo com a sua necessidade, ou que supervisiona uma atividade em grupo ou projeto sendo desenvolvido pelo aluno.

O modelo blended misturado consiste no cenário no qual o aluno opta por realizar uma ou mais disciplinas totalmente on-line para complementar as disciplinas presenciais. É o caso, por exemplo, de a grade curricular oferecida presencialmente não dispor de disciplinas de interesse do aluno, e que são oferecidas on-line. 
No modelo virtual enriquecido, a ênfase está nas disciplinas que o aluno realiza on-line, sendo que ele pode realizar algumas atividades presencialmente como, por exemplo, experiências práticas, laboratórios ou mesmo uma disciplina presencial. Esse modelo difere do blended misturado pelo fato de a maior parte do ensino estar acontecendo on-line, complementado com poucas atividades presenciais.

Finalmente, o modelo rodízio consiste em proporcionar ao aluno a chance de alternar ou circular por diferentes modalidades de aprendizagem. Esse modelo está dividido em outros quatro subgrupos. Um deles, o rodízio entre estações, consiste em proporcionar ao aluno a possibilidade de circular, dentro da sala de aula, por diferentes estações, sendo uma delas uma estação de aprendizagem on-line, outra de desenvolvimento de projeto, trabalho em grupo ou interagindo com o professor, tirando dúvidas. Um segundo subgrupo é o rodízio entre laboratórios, no qual o aluno circula em diferentes espaços dentro do campus, sendo um deles o laboratório no qual ele realiza atividades on-line, ou laboratórios para o desenvolvimento de práticas específicas. $O$ terceiro subgrupo é o rodízio individual, no qual o aluno circula entre diferentes modalidades de aprendizagem de acordo com horários prefixados. O quarto subgrupo, denominado sala de aula invertida (flipped classroom), será discutido no próximo tópico.

A combinação do que ocorre on-line com o que ocorre em sala de aula presencialmente pode ser muito rica e beneficiar a aprendizagem dos alunos sob todos os aspectos. O uso da modalidade blended learning tem sido a tendência em muitos cursos de EaD. No Brasil, Moran acredita que essa é a modalidade que pode introduzir mudanças no ensino presencial e nas disciplinas ou cursos realizados a distância. Segundo esse autor, "As instituições utilizarão o blended como o modelo predominante de educação, que unirá o presencial e o EaD. Os cursos presenciais se tornarão semipresenciais, principalmente na fase mais adulta da formação, como a universitária." (MORAN, 2014).

\section{A sala de aula invertida (ou flipped classroom)}

A sala de aula invertida é uma modalidade de e-learning na qual o conteúdo e as instruções são estudados on-line antes de o aluno frequentar a sala de aula, que agora passa a ser o local para trabalhar os conteúdos já estudados, realizando atividades práticas como resolução de problemas e projetos, discussão em grupo, laboratórios etc. A inversão ocorre uma vez que no ensino tradicional a sala de aula serve para o professor transmitir informação para o aluno que, após 
a aula, deve estudar o material que foi transmitido e realizar alguma atividade de avaliação para mostrar que esse material foi assimilado. Na abordagem da sala de aula invertida, o aluno estuda antes da aula e a aula se torna o lugar de aprendizagem ativa, onde há perguntas, discussões e atividades práticas. $\mathrm{O}$ professor trabalha as dificuldades dos alunos, ao invés de apresentações sobre o conteúdo da disciplina (EDUCAUSE, 2012).

O tipo de material ou atividades que o aluno realiza on-line e na sala de aula variam de acordo com a proposta sendo implantada, criando diferentes possibilidades para essa abordagem pedagógica.

As regras básicas para inverter a sala de aula, segundo o relatório Flipped Classroom Field Guide (2014), são: 1) as atividades em sala de aula envolvem uma quantidade significativa de questionamento, resolução de problemas e de outras atividades de aprendizagem ativa, obrigando o aluno a recuperar, aplicar e ampliar o material aprendido on-line; 2) Os alunos recebem feedback imediatamente após a realização das atividades presenciais; 3) Os alunos são incentivados a participar das atividades on-line e das presenciais, sendo que elas são computadas na avaliação formal do aluno, ou seja, valem nota; 4) tanto o material a ser utilizado on-line quanto os ambientes de aprendizagem em sala de aula são altamente estruturados e bem planejados.

A ideia da sala de aula invertida não é nova e foi proposta inicialmente por Lage, Platt e Treglia (2000), concebida como "inverted classroom" e usada pela primeira vez em uma disciplina de Microeconomia em 1996 na Miami University (Ohio, EUA). Essa abordagem foi implantada por esses autores em resposta à observação de que o formato de aula tradicional era incompatível com alguns estilos de aprendizagem dos alunos. Com isso eles planejaram a disciplina na qual os alunos realizavam, antes da aula, leituras de livros didáticos, assistiam a vídeos com palestras e apresentações em PowerPoint com superposição de voz. Para garantir que os alunos estudassem o material, eles tinham que completar uma lista de exercícios que era gerada aleatoriamente e avaliada periodicamente, valendo nota. $\mathrm{O}$ tempo de aula era gasto em atividades que incentivavam os alunos a processar e aplicar os princípios de economia, em minipalestras que os professores apresentavam em resposta às perguntas dos alunos, experiências sobre economia que um grupo de alunos tinha que resolver, ou discussão sobre resolução de problemas. Essa experiência foi comparada com outra disciplina, sobre o mesmo conteúdo, e ministrada segundo a abordagem tradicional. Sobre a aula invertida os alunos e o instrutor reportaram que a abordagem foi positiva, sendo que foi observado que os alunos pareciam mais motivados do que na disciplina ministrada em um formato tradicional.

Embora os resultados dessa experiência tenham sido publicados em 2000, ela não foi disseminada, principalmente por conta do fato de a questão 
dos estilos de aprendizagem ser um tópico controverso e pela dificuldade em preparar o material para ser usado fora da aula, considerando o desenvolvimento tecnológico no final dos anos 1990.

A partir dos anos 2010, o termo "flipped classroom" passou a ser um chavão, impulsionado em parte por publicações no The New York Times (FITZPATRICK, 2012); no Chronicle of Higher Education (BERRETT, 2012); e sobre as experiências na área de Ciências realizadas na Universidade de Harvard (MAZUR, 2009). A partir de então surgiram diversos exemplos de escolas de Ensino Básico e de Instituições de Ensino Superior que passaram a adotar a abordagem da sala de aula invertida.

\section{Exemplos de implantações da sala de aula invertida}

A abordagem da sala de aula invertida não deve ser novidade para professores de algumas disciplinas, nomeadamente no âmbito das ciências humanas. Nessas disciplinas, em geral, os alunos leem e estudam o material sobre literatura, filosofia, entre outros assuntos, antes da aula e, em classe, os temas estudados são discutidos. A dificuldade da inversão ocorre especialmente nas disciplinas das ciências exatas, nas quais a sala de aula é usada para passar o conhecimento já acumulado. Assim, a maior parte dos exemplos de inversão da sala de aula ocorre nesse âmbito.

O Flipped Classroom Field Guide (2014) apresenta diversos exemplos de disciplinas desenvolvidas em diferentes universidades, sendo a maior parte delas relativas à área das ciências exatas, com exceção de "História Global", "Desenvolvimento Demográfico" e "Nutrição e Saúde da Criança". As diferenças entre as experiências são justamente o tipo de material e os recursos usados na atividade on-line, e o que é desenvolvido em sala de aula. Geralmente fora da aula são vídeos previamente gravados ou material encontrado na internet, previamente selecionado pelo professor, leitura de textos ou livros didáticos, e resposta a uma série de questões de avaliação sobre o material estudado. Nas aulas presenciais os alunos resolvem problemas, individualmente ou em grupo, realizam atividades práticas, discussão do material ou são ministradas pequenas palestras relativas aos assuntos que os alunos não compreenderam.

Dois exemplos bastante distintos são utilizados na Harvard University e no MIT. Ambos adotaram a estratégia da sala de aula invertida, implantada em algumas disciplinas. Essas universidades têm inovado seus métodos de ensino, procurando adequá-los para que possam explorar os avanços das tecnologias 
educacionais, bem como minimizar a evasão e o nível de reprovação em disciplinas como Física.

A Harvard introduziu o método Peer Instruction (PI), desenvolvido pelo Prof. Eric Mazur. O PI consiste em prover material de apoio de modo que o aluno possa estudar o conteúdo antes de frequentar a sala de aula. Com base no material estudado, o aluno responde a um conjunto de questões, via um Learning Management System (LMS). O professor, antes de ministrar a aula, verifica as questões mais problemáticas e que devem ser trabalhadas em sala de aula. Durante a aula, as discussões são intercaladas com Concept Tests, destinados a expor as dificuldades que os alunos encontram. Esses testes são respondidos via sistema de resposta interativo, tipo clicker, de modo que a classe e o professor possam acompanhar o nível de compreensão sobre os conceitos em discussão. Antes de responder o teste, os alunos têm um ou dois minutos para pensar sobre a questão e formular suas próprias respostas. Dependendo da resposta, se uma grande porcentagem de alunos da classe (geralmente entre $30 \mathrm{e}$ $65 \%$ ) responde incorretamente, então os alunos devem discutir essa questão em pequenos grupos, enquanto os instrutores circulam pela classe para promover discussões produtivas. Os estudantes passam dois ou três minutos discutindo suas respostas na tentativa de chegar a um consenso sobre a resposta correta. Esse processo obriga os alunos a pensarem sobre os argumentos a serem desenvolvidos, e permite que eles (assim como o professor) possam avaliar o nível de compreensão sobre os conceitos antes mesmo de deixar a sala de aula. Após essa discussão os alunos respondem à questão conceitual novamente. $\mathrm{O}$ instrutor fornece feedback, explicando a resposta correta e complementando com questões relacionadas, se necessário. O ciclo é então repetido com outro tema, sendo cada ciclo tipicamente de 13-15 minutos.

Utilizando-se essa estratégia, foi verificado que os estudantes apresentam ganhos significativos na compreensão conceitual, avaliados com testes padronizados, bem como ganham habilidades para resolver problemas comparáveis aos adquiridos nas aulas tradicionais (CROUCH; MAZUR, 2001). Esta metodologia foi utilizada inicialmente na disciplina introdutória de Física Aplicada e atualmente está sendo introduzida em outros cursos e disciplinas, inclusive sendo usada para atrair alunos para as áreas de ciências, tecnologia, engenharia e matemática (WATKINS; MAZUR, 2013).

O MIT desenvolveu o Projeto TEAL/Studio Physics, cujo responsável é o Prof. John Belcher (2001). Classes de aulas tradicionais foram transformadas em Estúdio de Física e a metodologia de ensino é baseada no "Technology Enabled Active Learning" (TEAL). Essa abordagem está sendo utilizada nas disciplinas introdutórias de Física: "Introductory Mechanics" (8.01) e "Electricity and 
Magnetism" (8.02), ministradas para todos os alunos que ingressam no MIT (cerca de 1.000 por ano).

A Figura 1 mostra a organização de uma das salas TEAL/Estúdio de Física. São duas salas, uma para cada disciplina, tendo cada uma 3.000 metros quadrados, contendo uma estação de trabalho no centro da sala para o instrutor, cercado por 13 mesas redondas. Em cada mesa sentam-se três grupos de três alunos, sendo que cada grupo conta com um computador para exibir slides das aulas, acessar informação e coletar dados de experimentos.

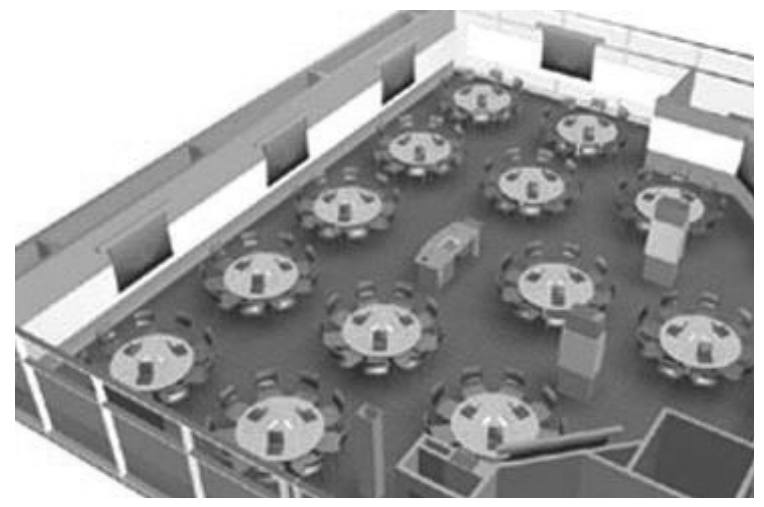

FIGURA 1 - SALA DE AULA DO TEAL/ESTÚDIO DE FÍSICA

Os grupos são formados por alunos com diferentes níveis de conhecimento. Antes da aula, o aluno deve estudar o material de apoio e responder, via plataforma on-line, um conjunto de questões (similar ao método PI). Durante a aula, o professor apresenta o material em aproximadamente 20 minutos, intercalados com questões para discussão, visualizações e exercícios de lápis e papel. Os alunos usam simulações animadas, desenvolvidas para ajudá-los a visualizar conceitos e realizar experimentos em grupos, com o auxílio do computador na aquisição e análise dos dados. O professor faz perguntas periodicamente sobre conceitos, e os alunos discutem e respondem através do sistema de resposta interativo.

Por intermédio do Projeto TEAL/Studio Physics o MIT conseguiu bons resultados com relação ao aproveitamento dos alunos, reduzindo a taxa de reprovação nas disciplinas, que era de aproximadamente $15 \%$, e aumentando a frequência no final do semestre, que era inferior a 50\% (BELCHER, 2001).

Tanto a Harvard quanto o MIT realmente inovaram em termos da estrutura e dinâmica da sala de aula, inclusive o MIT alterou a configuração arquitetônica da sala de aula. No entanto, essa abordagem pode ser implantada por meios de soluções mais simples. 


\section{Como implantar a abordagem da sala de aula invertida}

Muitos professores podem estar usando estratégias de ensino que têm alguma semelhança com a sala de aula invertida. Eles podem não estar conscientes sobre essa terminologia ou sobre as concepções aqui apresentadas. No entanto, como mencionam Bergmann e Sams em seu livro Flip Your Classroom: Reach Every Student in Every Class Every Day (2012), baseado no trabalho pioneiro sobre a implantação da sala de aula invertida em suas disciplinas do Ensino Médio americano: os professores podem iniciar com o básico sobre a inversão da sala de aula, e à medida que vão adquirindo experiência passam a usar a aprendizagem baseada em projeto ou na investigação e, com isso, vão se reinventando, criando cada vez mais estratégias centradas nos estudantes ou centradas na aprendizagem, ao invés das aulas expositivas que costumavam ministrar.

Os aspectos fundamentais da implantação da sala de aula invertida são a produção de material para o aluno trabalhar on-line e o planejamento das atividades a serem realizadas na sala de aula presencial.

Sobre os materiais on-line, a maior parte das estratégias implantadas utiliza vídeos que o professor grava a partir de aulas presenciais ou que grava usando um software como, por exemplo, o Camtasia Studio. Esse software capta qualquer informação da tela do computador que o professor está usando, sua voz, sua imagem gravada via câmera do computador e qualquer anotação que é feita com a caneta digital. No entanto, é preciso dosar o número de vídeos e o tamanho dos vídeos. A ideia não é substituir a aula presencial por vídeos, pois os alunos reclamam do fato de a aula expositiva ser "chata" e essa mesma aula transformada em vídeo pode ficar mais chata ainda!

É importante o professor pensar que as TDIC oferecem outros recursos a serem explorados pedagogicamente, como animações, simulações ou mesmo o uso de laboratórios virtuais que o aluno pode acessar e complementar as leituras ou mesmo os vídeos mais pontuais que ele assiste. A ideia é realmente integrar as TDIC nas atividades curriculares, como proposto por Almeida e Valente (2011).

Finalmente, para que o professor possa saber o que o aluno absorveu desse estudo on-line, praticamente todas as soluções de sala de aula invertida sugerem que o estudante realize um teste, elaborado na própria plataforma on-line, de modo que possa avaliar sua aprendizagem. Os resultados dessa avaliação, quando registrados na plataforma, permitem ao professor acessá-los e conhecer quais foram os pontos críticos do material estudado e que devem ser retomados em sala de aula. 
Sobre o planejamento das atividades presenciais em sala de aula, o mais importante é o professor explicitar os objetivos a serem atingidos com sua disciplina, e propor atividades que sejam coerentes e que auxiliam os alunos no processo de construção do conhecimento. Essas atividades podem ser hands on, discussão em grupo, resolução de problemas etc. No entanto, em todos esses casos é fundamental que o aluno receba feedback sobre os resultados das ações que realizam. A sala de aula presencial assume um papel importante nessa abordagem pedagógica pelo fato de o professor estar observando e participando das atividades que contribuem para o processo de significação das informações que os estudantes adquiriram estudando on-line. Nesse sentido, o feedback é fundamental para corrigir concepções equivocadas ou ainda mal elaboradas.

Algumas atividades em sala de aula podem ser mais estruturadas, como a proposta por Bergmann e Sams (2012) denominada "flipped mastery", um modelo no qual os alunos, em seu ritmo, progridem para novos objetivos somente após ter dominado os anteriores. Ou mais desafiadoras, como propostas por Driscoll (2014), que usou os conceitos de jogos para transformar todas as avaliações em missões que proporcionam pontos à medida que os estudantes progridem.

Para as instituições que têm a intenção de implantar essa abordagem pedagógica é importante iniciar com um conjunto de professores que têm interesse de inverter suas salas de aula. Portanto, não deve ser algo imposto ao professor.

Outro fator importante é iniciar com um pequeno grupo de professores, antes de adotar soluções nas quais todos embarquem nessa nova proposta. É possível que essas iniciativas mais pontuais sejam passíveis de serem implantadas sem que haja uma reestruturação educacional e sem que seja montada a infraestrutura tecnológica e de apoio para a produção de material educacional. O envolvimento de um grande número de professores e a implantação de ações pedagógicas inovadoras na instituição educacional como um todo demanda a instalação de infraestrutura adequada e de apoio aos professores, como afirmam Fullan e Smith (1999): é possível criar inovações nas instituições educacionais que duram por alguns anos. Porém, a sustentabilidade de processos inovadores necessita de uma boa infraestrutura e de suporte aos professores.

Diversas universidades americanas têm desenvolvido guias para auxiliar a implantação da sala de aula invertida, como o da Georgia Tech (MARGULIEUX; MAJERICH; MCCRACKEN, 2013), da Duke University (FERRERI, 2013) e da Vanderbilt University (BRAME, 2014). O portal Flipped Learning Network (2014) pertence a uma organização sem fins lucrativos e constitui uma importante fonte de informação para educadores em todos os níveis e disciplinas que estão empregando a inversão em sua sala de aula. 


\section{Por que inverter a sala de aula?}

As razões propostas podem ser classificadas em dois conjuntos: um, com base em argumentos teóricos; outro, com base em resultados de estudos que indicam o sucesso educacional dessa abordagem. Por outro lado, existem autores que ainda não estão convencidos que essa abordagem é a solução para os problemas como evasão e repetência enfrentados pela educação superior atualmente.

Com base em uma das conclusões sobre a ciência da aprendizagem mencionada por Bransford, Brown e Cocking (2000), na sala de aula invertida os estudantes estão adquirindo os conhecimentos factuais antes de entrar na sala de aula. A concentração nas formas mais elevadas do trabalho cognitivo, ou seja, a aplicação, análise, síntese, significação e avaliação desse conhecimento acontecem em sala de aula, onde eles têm o apoio de seus pares e do instrutor.

$\mathrm{O}$ fato de o estudante ter o contato com o material instrucional antes da sala de aula apresenta diversos pontos positivos. Primeiro, o aluno pode trabalhar com esse material no seu ritmo e tentar desenvolver o máximo de compreensão possível. Os vídeos gravados têm sido os mais utilizados pelo fato de o aluno poder assisti-los quantas vezes for necessário e dedicar mais atenção aos conteúdos que apresentam maior dificuldade. Por outro lado, se o material é navegável, com uso de recursos tecnológicos, como animação, simulação, laboratório virtual etc. ele pode aprofundar ainda mais seus conhecimentos.

Segundo, o estudante é incentivado a se preparar para a aula, realizando tarefas ou a autoavaliação que, em geral, fazem parte das atividades on-line. Com isso, o aluno pode entender o que precisa ser mais bem assimilado, captar as dúvidas que podem ser esclarecidas em sala de aula e planejar como aproveitar o momento presencial, com os colegas e com o professor.

Terceiro, o resultado da autoavaliação é uma indicação do nível de preparo do aluno. Ela sinaliza ao professor os temas com os quais os alunos apresentaram maior dificuldade e que devem ser trabalhados em sala de aula. Nesse sentido, o professor pode customizar as atividades da sala de aula de acordo com as necessidades dos alunos. O próprio aluno, de acordo com as deficiências observadas, pode identificar áreas nas quais ele precisa de ajuda. Essas dificuldades podem ser um ponto de partida para as atividades que ele seleciona.

Quarto, se o aluno se preparou antes do encontro presencial, o tempo da aula pode ser dedicado ao aprofundamento da sua compreensão sobre o conhecimento adquirido, tendo a chance de recuperá-lo, aplicá-lo e com isso, construir novos conhecimentos. De acordo com as conclusões de Bransford, Brown e Cocking (2000), essa é uma importante fase do processo de aprendizagem, e 
que no ensino tradicional o aluno realiza após a aula, e sem o apoio dos colegas e do professor. Na sala de aula invertida esse apoio acontece no momento em que o aluno mais necessita, ou seja, just in time.

Finalmente, as atividades em sala de aula incentivam as trocas sociais, entre colegas, como no caso do PI implantado em Harvard ou do trabalho em grupo que é realizado no TEAL/Estúdio de Física do MIT. Essa colaboração entre alunos, a interação do aluno com o professor são aspectos fundamentais do processo de ensino e de aprendizagem que a sala de aula tradicional não incentiva.

Outro conjunto de evidências para a inversão da sala de aula é proporcionado pelos estudos sobre a percepção e o desempenho dos alunos que participam de experiências que utilizam a abordagem da sala de aula invertida.

Ao longo do artigo foram mencionados os estudos realizados por Lage, Platt e Treglia (2000), que avaliaram a percepção dos alunos que realizaram disciplinas na modalidade invertida e na tradicional. Outros estudos mencionados foram os produzidos pela equipe de Eric Mazur da Harvard University e o estudo sobre o TEAL/Estúdio de Física, do MIT. Em todos eles a avaliação dos resultados do desempenho dos alunos que participaram de experiências usando a abordagem da sala de aula invertida foi muito positiva.

Os guias elaborados pelas universidades americanas mencionados acima também apresentam diversos exemplos e resultados de estudos mostrando os ganhos educacionais proporcionados pelas diferentes experiências de sala de aula invertida, como por exemplo, o guia da Vanderbilt University (BRAME, 2014).

Por outro lado, como qualquer outra iniciativa inovadora, a sala de aula invertida tem recebido críticas negativas, como foi observado por Hennick (2014). Por exemplo, alguns professores argumentam que, se já é difícil os alunos aprenderem por meio das exposições e apresentações no sistema tradicional, será ainda mais difícil aprender via atividades on-line ou assistindo a vídeos.

Outros críticos também afirmam que o modelo é bastante dependente da tecnologia, o que pode criar um ambiente de aprendizagem desigual. Se o aluno acessa a informação de sua casa e dispõe de acesso à tecnologia ele vai estar em vantangem com relação ao aluno que não dispõe dos recursos tecnológicos.

E o ponto considerado mais problemático é o fato de o aluno não se preparar antes da aula e, com isso, não ter condições de acompanhar o que acontece na sala de aula presencial.

Para todos esses argumentos existem contra-argumentos e soluções implantadas para superar essas dificuldades. Por exemplo, Bergmann e Sams (2012) gravam DVDs para os alunos que não dispõem de internet em casa. A solução para os alunos que não se preparam antes das aulas é a realização de tarefas ou autoavaliações que são computadas no processo de avaliação formal do aluno. 
No entanto, a crítica que mais preocupa é feita por Ian Bogost (2013), que entende que o fato de o professor estar preparando vídeos para os alunos assistirem antes das aulas, na verdade, está condensando a aula em um único formato, mais curto e necessariamente menos detalhado do que seria possível com uma combinação de leituras de livros didáticos. Com isso, o aluno nunca tem contato com materiais primários de autores especialistas na área, mas com o material que o professor processa e disponibiliza na forma de vídeos.

A outra preocupação é o barateamento do processo educacional que está em jogo. Está claro que o processo educacional é custoso e existem interesses para que mais alunos sejam atendidos com menos custo. Bogost entende que os alunos podem se sentir preparados com o estudo do material disponibilizado e a sala de aula contar com professores menos qualificados para simplesmente avaliar a aprendizagem do aluno. Nesse sentido, o que está sendo invertido são os piores aspectos da sala de aula tradicional.

Bogost (2013) torce para que as experiências da sala de aula invertida possam realmente ser melhoradas como uma prática social de longo prazo. Para tanto, seria necessário que os administradores e os comerciantes da educação passassem para o banco traseiro e que os educadores pudessem dispor dos recursos para realizar o que sabem e o que é melhor para a aprendizagem dos alunos, evitando que atalhos fossem impostos como inovação.

\section{Considerações finais}

Estamos vivendo um momento de grandes oportunidades do ponto de vista educacional, principalmente com a disseminação das TDIC e o fato de elas estarem adentrando a sala de aula. Os alunos, na sua maioria, dispõem dessas tecnologias e os que frequentam as aulas estão usando-as, porém, como e com que objetivo? Em alguns casos os professores estão sabendo explorar esses recursos, integrando-os às atividades que realizam. Porém, a maioria está se sentido desconfortável com o fato de o aluno não estar "prestando atenção" no que está sendo exposto pelo professor. Esses fatos têm mobilizado muitos coordenadores e professores dos cursos de graduação das instituições de ensino superior. Há um grande interesse em mudar e propor algo inovador, que possa resolver o problema da evasão, da falta de interesse dos estudantes pelas aulas e, consequentemente, o alto número de repetências em disciplinas, especialmente das ciências exatas. 
A sala de aula invertida tem sido uma solução implantada em universidades de renome, com grande apoio dos colegiados superiores, como foi mencionado ao longo do artigo. Os estudos sobre a percepção, bem como sobre o desempenho dos alunos apresentam resultados positivos. Além disso, essa abordagem pedagógica está fundamentada em diversas teorias e concepções sobre aprendizagem que indicam que os resultados educacionais podem ser muito mais promissores do que o processo de ensino tradicional baseado em aulas expositivas. Por outro lado, posições inovadoras como essas têm seus pontos negativos, como também foi discutido.

O objetivo desse artigo foi o de discutir e apresentar as experiências que estão sendo realizadas e como a sala de aula invertida pode auxiliar na renovação do ensino superior. O desejo é que gradativamente o sistema educacional superior se aproprie dessas ideais e as transforme em uma prática educacional e social produtiva para todos, principalmente para os professores e alunos.

\section{REFERÊNCIAS}

ALMEIDA, M. E. B.; VALENTE, J. A. Tecnologias e Currículo: trajetórias convergentes ou divergentes? São Paulo: Paulus, 2011.

BELCHER, J. Studio Physics at MIT. MIT Physics Annual, 2001. Disponível em: $<$ http:// web.mit.edu/jbelcher/www/PhysicsNewsLetter.pdf>. Acesso em: 15 ago. 2014.

BERGMANN, J.; SAMS, A. Flip Your Classroom: reach every student in every class every day. Eugene, Oregon: ISTE, 2012.

BERRETT, D. How 'flipping' the classroom can improve the traditional lecture. The Chronicle of Higher Education, Feb. 19, 2012.

BOGOST, I. The Condensed Classroom: "Flipped" classrooms don't invert traditional learning so much as abstract it. The Atlantic, 2013. Disponível em: <http://www.theatlantic.com/technology/archive/2013/08/the-condensed-classroom/279013/ > . Acesso em: 15 abr. 2014.

BRAME, C. J. Flipping the classroom. Disponível em: < http://cft.vanderbilt.edu/guides-sub-pages/flipping-the-classroom/>. Acesso em: 15 abr. 2014.

BRANSFORD, J. D.; BROWN, A. L.; COCKING, R. R. How people learn: Brain, mind, experience, and school. Washington, D.C.: National Academy Press, 2000.

BRASIL. Ministério da Educação, Secretaria de Educação Fundamental. Parâmetros Curriculares Nacionais $5^{a}$ a $8^{a}$ Séries. Brasília: MEC/SEF, 1998. Disponível em: $<$ http:// 
portal.mec.gov.br/index.php?option=com_content\&view=article\&id=12657:parame tros-curriculares-nacionais-5o-a-8o-series $\&$ catid=195: seb-educacao-basica $>$. Acesso em: 06 mar. 2014.

COURSEWARE. What is courseware? Disponível em: <http://courseware.stanford. edu/>. Acesso em: 06 mar. 2014.

CROUCH, C. H.; MAZUR, E. Peer Instruction: Ten years of experience and results. American Journal of Physics, v. 69, p. 970-977, 2001.

DAVIDSON, C. N. Now You See It: how technology and brain science will transform schools and business for the $21^{\text {st }}$ century. New York: Penguin Books, 2011.

DEWEY, J. (1916). Democracy and Education. Cópia revisada, 1944. New York: The Free Press, 1944.

DRISCOLL, T. Gamification Series Part 4: Our Quest (Flipped 101 - Flipped Mastery - Gamified Flip). 2014. Disponível em: <http://www.flipped-history.com/2014/03/ gamification-series-part-4-our-quest.html>. Acesso em: 15 abr. 2014.

EDUCAUSE: Things you should know about flipped classrooms. 2012. Disponível em: $<$ http://net.educause.edu/ir/library/pdf/eli7081.pdf >. Acesso em: 19 jul. 2013.

EDX. Disponível em: <https://www.edx.org/>. Acesso em: 06 mar. 2014.

FERRERI, E. Flipping Teaching Around: Duke professors flip the classroom to better their teaching. 2013. Disponível em: <https://today.duke.edu/2013/02/flippedclassroom\#>. Acesso em: 15 abr. 2014.

FITZPATRICK, M. Classroom lectures go digital. The New York Times, June 24, 2012. FLIPPED CLASSROOM FIELD GUIDE. Portal Flipped Classroom Field Guide. Disponível em: <http:/www.cvm.umn.edu/facstaff/prod/groups/cvm/@pub/@cvm/ @ facstaff/documents/content/cvm_content_454476.pdf>. Acesso em: 15 abr. 2014.

FLIPPED LEARNING NETWORK. Portal Flipped Learning Network Ning. Disponível em: <http://flippedclassroom.org/>. Acesso em: 04 abr. 2014.

FREIRE, P. Pedagogia do Oprimido. 17. ed. Rio de Janeiro: Paz e Terra, 1987.

FRIESEN, N. Report: defining blended learning. 2012. Disponível em: $<\mathrm{http}: / /$ learningspaces.org/papers/Defining_Blended_Learning_NF.pdf $>$. Acesso em: 04 abr. 2014.

FULLAN, M.; SMITH, G. Technology and the problem of change. 1999. Disponível em: < http://www.michaelfullan.ca/media/13396041050.pdf> . Acesso em: 06 mar. 2014.

GURI-ROSENBLIT, S. Distance Education in the Digital Age: common misconceptions and challenging tasks. Journal of Distance Education, v. 23, n. 2), p. 105-122, 2009.

HENNICK, C. Flipped 2.0. 2014. Disponível em: <http://www.scholastic.com/browse/ article.jsp?id=3758360 $>$. Acesso em: 06 mar. 2014. 
LAGE, M. J.; PLATT, G. J.; TREGLIA, M. Inverting the classroom: A gateway to creating an inclusive learning environment. The Journal of Economic Education, v. 31, p. 30-43, 2000.

MARGULIEUX, L.; MAJERICH, D.; MCCRACKEN, M. C21U's Guide to Flipping Your Classroom. 2013. Disponível em: <http://www.c21u.gatech.edu/sites/default/files/ Flipped\%20Classroom\%20Guide_final.pdf >. Acesso em: 15 abr. 2014.

MAZUR, E. Farewell, Lecture? Science, v. 323, p. 50-51, 2009.

MORAN, J. M. A EAD no Brasil: cenário atual e caminhos viáveis de mudança. 2014. Disponível em: <http://www2.eca.usp.br/moran/wp-content/uploads/2013/12/cenario. pdf>. Acesso em: 15 abr. 2014.

STAKER, H.; HORN, M. B. Classifying K-12 blended learning. Mountain View, CA: Innosight Institute, Inc. 2012. Disponível em: <http:/www.christenseninstitute.org/ wp-content/uploads/2013/04/Classifying-K-12-blended-learning.pdf $>$. Acesso em: 15 abr. 2014.

TAPSCOTT, D.; WILLIAMS, A. D. Innovating the 21st-Century University: It's Time! Educause Review, January/February 17-29, 2010. Disponível em: <http://net.educause. edu/ir/library/pdf/ERM1010.pdf>. Acesso em: 15 abr. 2014.

UNESCO. 2009 World Conference on Higher Education: the new dynamics of higher education and research for societal change and development. Paris: UNESCO, 2009. Disponível em: <http://www.unesco.org/fileadmin/MULTIMEDIA/HQ/ED/ED/pdf/WCHE _2009/FINAL\%20COMMUNIQUE\%20WCHE\%202009.pdf. Acesso em: 15 abr. 2014.

VALENTE, J. A. A crescente demanda por trabalhadores mais bem qualificados: a capacitação para a aprendizagem continuada ao longo da vida. In: VALENTE, J. A.; MAZZONE, J.; BARANAUSKAS, M. C. C. (Orgs.). Aprendizagem na era das tecnologias digitais. São Paulo: Cortez: FAPESP, p. 48-72, 2007.

WATKINS, J.; MAZUR, E. Retaining students in science, technology, engineering, and mathematics (STEM) majors. J. Coll. Sci. Teach., v. 42, n. 5, p. 36-41, 2013. Disponível em: <http://www.cssia.org/pdf/20000243-RetainingStudentsinSTEMMajors.pdf>. Acesso em: 16 ago. 2013.

Texto recebido em 21 de novembro de 2014. Texto aprovado em 08 de dezembro de 2014. 
